\title{
Differences in durations of stay for surgery in the NHS and private sector in England and Wales
}

\author{
B T WILLIAMS, J P NICHOLL, K J THOMAS, J KNOWELDEN
}

\begin{abstract}
Median durations of stay in England and Wales for eight "marker" operations were consistently shorter for patients in pay beds in the National Health Service than for patients in independent acute hospitals or public sector beds. This pattern was seen for both preoperative and postoperative stay and among specific age groups. Differential use of other hospitals for part of the period of care was not a factor, except for patients having hip replacement operations treated in NHS pay beds, one in seven of whom appeared to transfer to public sector care postoperatively.

These findings suggest that there is scope for a possible further reduction in durations of stay in public sector beds and, within the private sector, for an assessment of whether spells in independent hospitals need be longer than in NHS pay beds.
\end{abstract}

\section{Introduction}

In 1981 one eighth of all elective surgical operations on residents of England and Wales were performed in the private sector, with a ratio of three in independent hospitals to one in pay beds in National Health Service hospitals. ${ }^{1}$ The types of elective operation performed in the NHS and private sector were similar, but median durations of stay were observed to be generally shortest in NHS pay beds, intermediate in independent hospitals, and longest in NHS beds. One possible explanation for this is that managerially the private sector is more efficient. If this is the case, and assuming similar clinical outcomes, the NHS may be challenged to match the performance of the private sector. In this paper we explore these differences further and discuss their importance.

\section{Methods}

Data from the Hospital Inpatient Enquiry for 1980, the latest available year, covering a $10 \%$ sample of discharges of inpatients from NHS nonpaying beds and pay beds in England and Wales, were supplied on magnetic tape by the Office of Population Censuses and Surveys. The records of a sample of 12959 patients drawn from 150 of the 153 independent acute hospitals functioning at any time in England and Wales in 1981 were abstracted. The method of sampling and the way in which estimates were obtained for independent hospitals have been described

\footnotetext{
Medical Care Research Unit, Department of Community Medicine, University of Sheffield Medical School, Sheffield S10 2 RX

B T WILLIAMS, MD, FFCM, professor and head of department J P NICHOLL, BA, MSC, statistician

K J THOMAS, MA, research assistant

J KNOWELDEN, MD, FRCP, emeritus professor

Correspondence to: Professor Williams.
}

previously. ${ }^{2}$ For both NHS and independent hospitals the data included the patient characteristics of sex, age, area of residence, and source of admission and certain management details-namely, the operation performed; the place to which patients were discharged; and dates of admission, operation, and discharge, from which the durations of preoperative and postoperative stays were derived. The method of payment was obtained for patients of independent hospitals, but this was not available for patients in NHS pay beds. For NHS hospitals elective cases were identified as those admitted from waiting lists or as booked cases. All but a negligible number of admissions to independent hospitals had been previously arranged. The comparison was limited to residents of England and Wales. Patients admitted for abortion were excluded.

The criteria for inclusion for the "marker" operations were that the complexity of the procedure should be fairly constant and that the operation should be performed in the private sector and on a large number of NHS patients. In aggregate the eight operations selected represented nearly a quarter of the private sector's domestic inpatient elective surgical caseload, and one sixth of that of the NHS.

\section{Results}

For each operation the estimated median duration of completed stay was, as previously, ${ }^{1}$ observed to be shorter among the NHS paying patients than among either NHS public sector (non-paying) patients or patients in independent hospitals (table I). Typically, the duration of stay in the independent hospitals was intermediate to those in the other two types of beds. The median duration of stay in NHS pay beds for total hip replacement was 10.8 days, and in independent hospitals 14.9 days, while the median stay in NHS non-paying beds in the 14 English health regions and Wales ranged from 15.9 to 21.2 days - that is, in no region did these public sector patients move out of hospital as expeditiously as, nationally, private sector patients.

Within NHS hospitals the differences between paying and non-paying patients ranged from one day for cholecystectomy to nine days for total hip joint replacement. The $95 \%$ confidence intervals for the medians, ${ }^{3}$ also shown in table I, provide strong evidence that the median duration of stay in NHS pay beds is shorter than in NHS non-paying beds for all the eight operations, apart perhaps for cholecystectomy.

The pattern of differences in median durations of total stay was similar for the preoperative component of duration of stay. A Friedman two way analysis of variance by ranking to test whether the median preoperative durations of stay were the same in each sector was highly significant $\left(\chi_{2}^{2}=13.6, p<0.001\right)$, providing strong evidence that there were real differences between the sectors. For each operation preoperative stay was longest in the NHS non-paying group; for total hip joint replacements performed in NHS hospitals non-paying patients were admitted an entire day earlier than paying patients.

For each operation the postoperative stay was also shorter for the NHS paying patients than for the non-paying patients, by as much as eight days for total hip joint replacement. The overall differences among the three groups of patients were again highly significant $\left(\chi_{2}^{2}=12 \cdot 0, p=0.001\right)$ In this case, however, the difference lay between the NHS pay beds on the one hand and, on the other, the independent hospital and NHS non-paying beds, which had similar median postoperative durations of stay.

Duration of stay in hospital was related to age. The proportion of private patients who were in the earning age group 15-64 was $75 \%$ compared with $66 \%$ of NHS patients. The fact that NHS patients were older might in part have accounted for their longer durations of stay. However, for tonsil- 
lectomy, an operation performed mainly on children, the same gradation of duration of stay among the groups was evident. Moreover, for each operation in specific age groups the shortest median duration of stay was always for NHS paying patients, and the longest was usually for the nonpaying NHS group (table II). The differences in the medians were again highly significant $\left(\chi_{2}^{2}=19.9, p<0.001\right)$, indicating that, even given the age and type of operation, paying patients in the NHS had shorter durations of stay than non-paying patients, who had similar stays to patients in independent hospitals.

Another possible explanation of the differences in length of stay concerns the place to which patients are discharged. NHS non-paying patients may remain in hospital longer than their private sector equivalents because proportionately more of them receive all their convalescent care in the hospital in which the operation is undertaken. By contrast, private sector patients in independent hospitals or NHS pay beds may choose to convalesce in less expensive, more congenial, or more local institutions, thus reducing their duration of postoperative stay in the first hospital. Table III shows the proportion of patients discharged directly home after the eight selected operations. In fact, most patients in each sector returned home on discharge from hospital. However, patients undergoing hip joint replacement (a procedure that requires considerable postoperative care) were much less likely to be discharged home than those undergoing other operations. Over a quarter of such NHS pay bed patients received further care in a different institution. The durations of stay for patients undergoing hip joint replacement who were discharged alive other than to their homes were, for each group, shorter than those of patients discharged home directly (table IV). The same gradient as before was noted among the three groups, both for patients discharged home and for those discharged elsewhere. The greatest contrast within any group, however, was among NHS pay bed patients. The median duration of stay of patients discharged other than to their homes was only one third of that of those going home. This compared with one half in the independent hospital group and over three quarters in the NHS non-paying group.

Table $\mathrm{V}$ shows the places to which patients who underwent hip joint replacement were discharged if they were not discharged home. Three quarters of the patients treated in independent hospitals transferred to other independent facilities, most to private nursing homes, which presumably cost less. A further one fifth, representing $1.6 \%$ of the independent hospitals' caseload of hip joint replacements, were known to have transferred to unspecified NHS facilities. This may be an underestimate as exact information on such transfers was not always provided. Of the 1580 NHS non-paying patients who were not discharged home, $89 \%$ were transferred to other NHS facilities, one in four of these to NHS convalescent homes and the remainder to alternative hospital accommodation. The pattern of discharge from NHS pay beds was considerably different. Half of the patients not discharged home were admitted to NHS beds, more than a quarter completing their treatment in NHS convalescent facilities (one in seven of all pay bed patients undergoing hip joint
TABLE III-Percentages of patients discharged home after selected operations

\begin{tabular}{lccc}
\hline & Independent hospitals & NHS pay beds & NHS \\
\hline Tonsillectomy and adenoidectomy & 100 & 100 & 99 \\
Repair of inguinal hernia & 100 & 100 & 97 \\
Haemorrhoidectomy & 99 & 100 & 98 \\
Cholecystectomy & 98 & 93 & 91 \\
Hysterectomy & 98 & 99 & 93 \\
Total hip joint replacement & 92 & 71 & 91 \\
Excision internal structure knee & 100 & 100 & 97 \\
Varicose veins, ligation and stripping & 100 & 100 & 99
\end{tabular}

$\star$ Not elsewhere classified.

TABLE IV-Estimated median durations of completed stay in hospital (days) of patients discharged home or elsewhere after undergoing total hip joint replacement

\begin{tabular}{lccc}
\hline & Independent hospitals & NHS pay beds & NHS \\
\hline Home & $15 \cdot 2$ & $12 \cdot 5$ & $20 \cdot 0$ \\
Elsewhere & $8 \cdot 1$ & $4 \cdot 0$ & $15 \cdot 7$
\end{tabular}

TABLE V-Places to which patients undergoing hip joint replacement were discharged, excluding those discharged home. Figures in italic relate to all cases of hip joint replacement

\begin{tabular}{lccr}
\hline & $\begin{array}{c}\text { Independent } \\
\text { hospitals }\end{array}$ & $\begin{array}{c}\text { NHS } \\
\text { pay beds }\end{array}$ & \multicolumn{1}{c}{ NHS } \\
\hline $\begin{array}{l}\text { \% Who died } \\
\text { \% Discharged to: }\end{array}$ & $8(0 \cdot 6)$ & $4(0 \cdot 9)$ & $6(0 \cdot 6)$ \\
$\begin{array}{l}\text { NHS hospital } \\
\text { NHS convalescent facility }\end{array}$ & $19(1 \cdot 6)$ & $22(6 \cdot 2)$ & $68(6 \cdot 2)$ \\
$\begin{array}{l}\text { Private hospital or nursing home } \\
\text { Total No not discharged home estimated from } \\
\text { sample (=100\%) }\end{array}$ & $73(5 \cdot 8)$ & $28(7 \cdot 8)$ & $21(2 \cdot 0)$ \\
Total No of all patients estimated from sample & 309 & 650 & 1571 \\
$(=100 \%)$ & 3890 & 2310 & 17460 \\
$\%$ Of patients not discharged home & $7 \cdot 1)$ & $3(0 \cdot 2)$ \\
\hline & & $28 \cdot 1$ & $8 \cdot 9$ \\
\hline
\end{tabular}

replacements). They may, of course, have occupied these convalescent beds as paying patients, but this suggestion was not supported by the data available from the Hospital Inpatient Enquiry, in which the estimated total number of patients admitted as paying patients to the convalescent specialty or general practitioner hospitals having transferred from NHS hospitals was substantially less than the estimated total number of paying patients shown to have transferred out of pay beds to complete their treatment in other NHS facilities. The remaining patients, one in eight of

TABLE I-Estimated median duration of stay (days), and $95 \%$ confidence interval for median total stay, for selected operations on residents of England and Wales

\begin{tabular}{|c|c|c|c|c|c|c|c|c|c|}
\hline \multirow[b]{2}{*}{ Operation (OPCS code) } & \multicolumn{3}{|c|}{ Preoperative stay } & \multicolumn{3}{|c|}{ Postoperative stay } & \multicolumn{3}{|c|}{ Total stay ( $95 \%$ confidence interval) } \\
\hline & $\begin{array}{l}\text { Independent } \\
\text { hospitals }\end{array}$ & NHS pay beds & NHS & $\begin{array}{l}\text { Independent } \\
\text { hospitals }\end{array}$ & NHS pay beds & NHS & $\begin{array}{l}\text { Independent } \\
\text { hospitals }\end{array}$ & NHS pay beds & NHS \\
\hline Tonsillectomy and adenoidectomy (233) & $1 \cdot 2$ & 0.8 & 1.5 & 1.9 & 1.5 & $2 \cdot 1$ & $3 \cdot 1(2 \cdot 8 \cdot 3 \cdot 3)$ & $2 \cdot 3(1 \cdot 8-2 \cdot 6)$ & $3 \cdot 6(3 \cdot 6-3 \cdot 7)$ \\
\hline Repair of inguinal hernia (411) & 1.4 & 1.2 & 1.5 & 4.5 & $3 \cdot 0$ & $4 \cdot 0$ & $5.9(5 \cdot 6-6 \cdot 5)$ & $4 \cdot 2(3 \cdot 8 \cdot 4 \cdot 6)$ & $5 \cdot 5(5 \cdot 3-5 \cdot 6)$ \\
\hline Haemorrhoidectomy (493) & 1.4 & 1.1 & 1.6 & 6.0 & 3.9 & 5.8 & $7 \cdot 4(6 \cdot 8-8 \cdot 1)$ & $5 \cdot 0(4 \cdot 3 \cdot 6 \cdot 7)$ & $7 \cdot 4(7 \cdot 1 \cdot 7 \cdot 6)$ \\
\hline Cholecystectomy (522) & $1 \cdot 4$ & $1 \cdot 4$ & 1.7 & 8.6 & 84 & $9 \cdot 0$ & $10 \cdot 0(9 \cdot 3-10 \cdot 7)$ & $9.8(8 \cdot 9-10 \cdot 8)$ & $10 \cdot 7(10 \cdot 5-10 \cdot 8)$ \\
\hline Hysterectomy $\star^{\star}(696)$ & 1.4 & 1.4 & 1.9 & $9 \cdot 4$ & $8 \cdot 4$ & $9 \cdot 3$ & $10 \cdot 8(10 \cdot 4-11 \cdot 3)$ & $9 \cdot 8(9 \cdot 1-10 \cdot 4)$ & $11 \cdot 2(11 \cdot 0-11 \cdot 4)$ \\
\hline Total hip replacement $(810)$ & 1.7 & 1.5 & $2 \cdot 5$ & $13 \cdot 2$ & $9 \cdot 3$ & $17 \cdot 3$ & $14 \cdot 9(14 \cdot 0-16 \cdot 2)$ & $10 \cdot 8(9 \cdot 1-12 \cdot 5)$ & $19 \cdot 8(19 \cdot 4-20 \cdot 2)$ \\
\hline Excision of internal structure knee $(820)$ & $1 \cdot 2$ & 1.2 & 1.6 & $4 \cdot 3$ & $3 \cdot 7$ & $5 \cdot 2$ & $5 \cdot 5(5 \cdot 0-6 \cdot 1)$ & $4 \cdot 9(4 \cdot 2 \cdot 6 \cdot 1)$ & $6 \cdot 8(6 \cdot 5-7 \cdot 1)$ \\
\hline Varicose veins, ligation and stripping (893/4) & $1 \cdot 1$ & 1.0 & 1.5 & $2 \cdot 9$ & $2 \cdot 3$ & 2.7 & $4 \cdot 0(3 \cdot 7 \cdot 4 \cdot 4)$ & $3 \cdot 3(2 \cdot 9 \cdot 3 \cdot 7)$ & $4 \cdot 2(4 \cdot 0 \cdot 4 \cdot 3)$ \\
\hline
\end{tabular}

$\stackrel{\star}{N}$ Not elsewhere classified.
OPCS $=$ Office of Population Censuses and Surveys.

TABLE II-Estimated median duration of completed stay (days) for selected operations on residents of England and Wales according to age

\begin{tabular}{|c|c|c|c|c|c|c|c|c|c|}
\hline \multirow[b]{2}{*}{ Operation (OPCS code) } & \multicolumn{3}{|c|}{$15-44$ years } & \multicolumn{3}{|c|}{$45-64$ years } & \multicolumn{3}{|c|}{$65+$ years } \\
\hline & $\begin{array}{l}\text { Independent } \\
\text { hospitals }\end{array}$ & $\begin{array}{c}\text { NHS } \\
\text { pay beds }\end{array}$ & NHS & $\begin{array}{l}\text { Independent } \\
\text { hospitals }\end{array}$ & $\begin{array}{c}\text { NHS } \\
\text { pay beds }\end{array}$ & NHS & $\begin{array}{l}\text { Independent } \\
\text { hospitals }\end{array}$ & $\begin{array}{c}\text { NHS } \\
\text { pay beds }\end{array}$ & NHS \\
\hline $\begin{array}{l}\text { Repair of inguinal hernia }(411) \\
\text { Haemorhoidectomy }(493) \\
\text { Cholecystectomy }(522) \\
\text { Hysterectomyt }(696) \\
\text { Total hip replacement }(810) \\
\text { Excision of internal structure knee }(820) \\
\text { Varicose veins, ligation and stripping }(893 / 4)\end{array}$ & $\begin{array}{r}5.6 \\
7.4 \\
9.7 \\
10.5\end{array}$ & $\begin{array}{c}3 \cdot 6 \\
6 \cdot 4 \\
9 \cdot 1 \\
9 \cdot 9 \\
\star \\
4 \cdot 8 \\
2 \cdot 9\end{array}$ & $\begin{array}{r}5.3 \\
7.0 \\
9.6 \\
10.9\end{array}$ & $\begin{array}{r}6 \cdot 0 \\
7 \cdot 4 \\
9 \cdot 9 \\
11 \cdot 4 \\
13 \cdot 6 \\
4 \cdot 5 \\
4 \cdot 4\end{array}$ & $\begin{array}{r}4 \cdot 4 \\
4 \cdot 7 \\
9 \cdot 7 \\
9 \cdot 5 \\
11 \cdot 0 \\
4 \cdot 7 \\
3 \cdot 5\end{array}$ & $\begin{array}{r}5 \cdot 9 \\
7 \cdot 4 \\
10 \cdot 7 \\
11 \cdot 7 \\
18 \cdot 7 \\
7 \cdot 1 \\
4 \cdot 3\end{array}$ & $16 \cdot 7$ & $\begin{array}{c}5 \cdot 1 \\
\star \\
\star \\
10 \cdot 8 \\
\star \\
\star\end{array}$ & $20 \cdot 5$ \\
\hline
\end{tabular}

* Fewer than 20 observations in one or more types of facility. 
all pay bed patients undergoing hip joint replacement, were discharged to independent hospitals or nursing homes.

One obvious possible determinant of how long patients stay in hospital is whether they pay for being there. Certainly, durations of stay were shorter for private sector patients than NHS non-paying patients. Furthermore, payment at the time of treatment may be a more powerful influence than payment spread out through insurance premiums. Information on this was available only for patients in the independent hospitals, and seven out of 10 episodes were financed through insurance schemes. Duration of stay was not consistently related to the method of payment for either short stay or longer stay operations.

\section{Discussion}

Differences in the duration of stay of public and private sector patients receiving similar treatment are probably due to the combined effects of several factors, even after the small but important age differential in the two groups of patients is allowed for. Most of the operations considered here are not usually performed on a day patient basis, so differential use in the two sectors of this mode of management was not considered.

Public sector patients may be slower to respond to developing medical problems than those who pay, and this would accord with what is known generally about the lower rates of use of most medical services among families of manual workers. Having deferred seeking specialist advice, many may then experience delay in obtaining a consultation. The surgeon will usually be able to operate sooner on patients who elect to pay than on NHS patients, who may consequently spend considerable periods on waiting lists, during which time their conditions may deteriorate or become more complicated. This may necessitate longer periods of both preoperative preparation and postoperative recovery. It is this group also whose home circumstances may be less conducive to early discharge. However, for patients undergoing hip joint replacement, the operation with the greatest contrasts in duration of stay, it is difficult to substantiate this theory. The age distributions of patients in each sector were similar, and so were the small proportions who died in hospital postoperatively. If on admission private patients were less severely affected the similarity in this measure of outcome might imply that they experienced less skilful management. More probably, however, the conditions were equally severe in each group to start with but paying patients were simply operated on and discharged sooner. Conceivably, after such a major operation private patients may actually be disadvantaged by their earlier discharge, through being removed from the acute hospital's rehabilitative services.

It is less easy to account for the differences in the durations of preoperative stay in the two sectors, particularly for operations like tonsillectomy and inguinal hernia, for which the amount of preparation is minimal. For more complex operations like cholecystectomy it is possible that on admission some NHS patients are subjected to more repeat tests than are necessary. For other patients clinicians might want to repeat certain investigations before operating, as their original studies may have preceded long periods of waiting for admission. A shorter period of preoperative stay may not in fact be to a patient's benefit as it limits his capacity to adjust to the surroundings and the capacity of nursing staff to form confidence building relationships with him.

Until 1980 the number of pay beds in NHS hospitals was progressively reduced. The change of government in 1979 brought a reversal in policy and the numbers are now increasing, though they have not reached their original level. Meanwhile the number of independent hospitals providing acute services has increased rapidly, reaching 178 in $1982 .{ }^{4}$ The consistently shorter durations of stay in NHS pay beds compared with the independent hospitals will therefore be of interest, both to patients paying out of their own pocket and to insurance carriers. A bed occupied for a longer period results in a higher "hotel" cost. Pay beds make up a very small part of an NHS hospital's complement, so in terms of total income and expenditure the hotel revenue from pay beds is relatively small. Independent hospitals, on the other hand, rely more heavily for revenue on having their beds occupied, so it is not surprising that, case for case, the patient stays in longer than in NHS pay beds. The economic interests of the consultant surgeons are served by achieving a high turnover but are unlikely to affect either part of the private sector differentially. In NHS hospitals, however, the proximity of pay beds to non-paying wards makes it easier for consultants to visit their private patients. Decisions to discharge may be taken with less delay than when visits to outlying independent hospitals are required. Further expansion of the numbers of NHS pay beds might therefore be expected to result in shorter inpatient episodes for the patients and to make it easier for consultants to maintain their levels of service to private patients while absorbing any increase in their NHS workload, which a reduction in the numbers of staff in training grades would imply. ${ }^{5}$ In some areas, however, the reverse is happening: patients and consultants are switching away from using NHS pay beds to the growing number of private hospitals with resulting loss of revenue to the NHS. ${ }^{6}$

Durations of stay in the NHS are consistently longer than those in the private sector. Some of this might possibly be accounted for by the different medical and social needs of the patients. The fact that the differences in the durations of stay between the paying and non-paying patients were the same for the preoperative component as for the postoperative component, even for minor operations, suggests, however, that this cannot provide the entire explanation. If the NHS is to take up a challenge to match the durations of stay recorded in the private sector close attention will have to be given to the quality of care received by the patient as well as the throughput achieved by the hospital. Our comparisons suggest, however, that NHS managers should question seriously whether the times spent in hospital before and after certain common operations need be as long as they are. For operations such as hernia repair early discharge has long been shown to be feasible for uncomplicated cases. ${ }^{7}$ Counterbalancing this is our evidence, which needs to be confirmed by more detailed studies, that the NHS is relieving the private sector, especially the pay bed component, of part of the postoperative care of some of its patients. This might occur when patients paying for themselves find that they can manage the costs of surgery but not all the costs of recuperation.

In the United States the Health Care Financing Administration (in relation to reimbursement through the Medicare scheme), some states, and some third party payers are now reimbursing hospitals on the principle that patients with similar medical conditions should receive similar care and use roughly the same amount of resources; therefore, the hospital should be reimbursed the same amount. ${ }^{8}$ If British third party payers were to consider a similar approach they might begin by questioning whether durations of stay in independent hospitals need be as long as they sometimes are.

We are grateful to the managers of the independent hospitals concerned for access to their data; to the Office of Population Censuses and Surveys for providing the 1980 Hospital Inpatient Enquiry tape; and to the Department of Health and Social Security and Trent Regional Health Authority who jointly fund the Medical Care Research Unit.

\section{References}

1 Nicholl JP, Thomas KJ, Williams BT, Knowelden J. The contributions of the private sector to elective surgery in England and Wales. Lancet 1984;ii:89-92.

2 Williams BT, Nicholl JP, Thomas KJ, Knowelden J. Analysis of the work of independent acute hospitals in England and Wales, 1981. Br Med J 1984;289:446-8.

3 Mackinnon WJ. Table for both the sign test and distributions-free confidence intervals for the median for sample sizes to 1,000. Foumal of the American Statistical Association 1964;59:935-56. 4 Department of Health and Social Security. Independent hospitals, nursing homes and clinics in England. London: DHSS, 1984.

5 Department of Health and Social Security. Medical manpower-the next twenty years. London: HMSO, 1978.

6 Timmins N. NHS losing cash to private hospitals. The Times 1984 September 11:2.

7 Morris D, Ward AWM, Handyside AJ. Early discharge after hernia repair. Lancet 1968;i:681-5.

8 National Center for Health Statistics. Diagnosis-related groups using data from the national hospital discharge survey: United States, 1981. Hyattsville, Md: National Center for Health Statistics, 1984. (Advance Data No 98.)

(Accepted 20 December 1984) 